WTC2005-63243

\title{
SENSIBILITY ANALYSIS OF DESIGN PARAMETERS FOR JOURNAL BEARINGS OPTIMIZATION OF MASS BALANCING SYSTEMS
}

\author{
Morais, L., Ferreira, L.A. \\ Depart. of. Mechanical Engineering and Industrial Management \\ Faculty of Engineering \\ University of Porto
}

\begin{abstract}
This work presents a sensibility analysis for the journal bearings of combustion engines mass balancing systems. Applying it, it's possible to improve the journal bearings and avoid possible failures.

This analysis consists on studying the effects of the variation of the journal bearings main parameters (radial clearance, journal bearing diameter and journal bearing length) on the journal bearings operating conditions (minimum film thickness, maximum pressure and power loss). The analysis also includes the comparison and selection of the different metallic materials that can be used in these journal bearings, as well as the selection of the lubrication system groove suitable for the journal bearings used in this kind of application.

This sensibility analysis shows that: increasing the radial clearance, the minimum film thickness increases, the maximum pressure remains approximately the same and the power loss decreases; increasing the journal bearing length, the minimum film thickness and power loss increase and the maximum pressure decreases; increasing the journal bearing diameter, the minimum film thickness and power loss increase and the maximum pressure decreases. At last, it's found that the white metals (Babbitts) are considered the most advantageous and indicated materials for these journal bearings, and that the lubrication system grooves should be circumferential.
\end{abstract}

\section{INTRODUCTION}

The journal bearings of these mass balancing systems sometimes have failures like fatigue, scuffing and wear. To avoid these failures and eventually optimize the journal bearings, this work presents one methodology [1] that consists on studying the effects of the one by one variation of the journal bearings design parameters (radial clearance, journal bearing diameter and journal bearing length) on the operating conditions of the journal bearings (minimum film thickness, maximum pressure and power loss). The methodology also comprehends the comparison between the metallic materials that can be used in these journal bearings, as well as, the selection of the lubrication groove suitable for this kind of application.

The journal bearings used in these systems are finite length journal bearings $(1 / 8<\mathrm{L} / \mathrm{D}<4)$ [2]. The Reynolds equation that describes their operation hasn't any analytical solution, so it is necessary to nondimensionalize it. Using the procedure proposed by Stachowiak and Batchelor [3], it is possible to solve it by numerical methods. So to solve the Reynolds equation and to calculate the operating conditions of the journal bearings, it was used the finite difference method with an 11 nodes finite difference mesh in both circumferential and axial direction. For the calculus of the operating conditions, it was also considered that there wasn't misalignment between the shaft and the journal bearing and that the mass balancing system housing was rigid and didn't suffer any deformation.

\section{METHODOLOGY}

To make this sensibility analysis one methodology was followed, with three steps [1]:

I. One by one variation of the journal bearing main parameters, this is, the variation of the radial clearance (c) maintaining the journal bearing's length and diameter; the variation of the journal bearing's diameter (D) maintaining the radial clearance and the length; the variation of the journal bearing's length (L) maintaining the diameter and the radial clearance. For each $\mathrm{c}, \mathrm{L}$ and $\mathrm{D}$ considered, the operating conditions of the journal bearings (minimum film thickness, maximum pressure and power loss) were calculated.

II. Analysis and comparison of the different metallic materials that can be used in these journal bearings.

III. Selection of the suitable lubricant groove for the journal bearings used in these mass balancing systems. 


\section{CASE STUDY}

To do this sensibility analysis it was considered one mass balancing system equipped with journal bearings of $\mathrm{L}=27 \mathrm{~mm}$ and $\mathrm{D}=20 \mathrm{~mm}$, operating with $\mathrm{c}_{\max }=25 \mu \mathrm{m}$ (maximum radial clearance) and $\mathrm{c}_{\min }=15 \mu \mathrm{m}$ (minimum radial clearance).

The engine rotational velocities considered for load calculus were: $850 \mathrm{rpm}, 1500 \mathrm{rpm}, 2000 \mathrm{rpm}, 3000 \mathrm{rpm}$ and $5000 \mathrm{rpm}$, simulating this way the idling, city use, road use, highway use and maximum engine rotation, respectively.

It was considered an SAE 0W40 oil with the following characteristics: $\rho=840 \mathrm{~kg} / \mathrm{m}^{3}$ (lubricant density), $v_{40^{\circ} \mathrm{c}}=73.6 \mathrm{cSt}$ (cinematic viscosity at $40{ }^{\circ} \mathrm{C}$ ) and $v_{100^{\circ} \mathrm{c}}=12.9 \mathrm{cSt}$ (cinematic viscosity at $100^{\circ} \mathrm{C}$ ); operating at $18^{\circ} \mathrm{C}$ (ambient temperature), $90^{\circ} \mathrm{C}$ (operating temperature) and $130^{\circ} \mathrm{C}$ (maximum temperature).

For the minimum film thickness two boundary values were considered: $3.20 \mu \mathrm{m}$ [4] and $2.15 \mu \mathrm{m}$. The first value is the allowable value for minimum film thickness and the second is the value from which occurs bearing-shaft contact.

It was also considered that the maximum pressure allowed by the journal bearings was $15 \mathrm{MPa}$ [5].

After analyzing this mass balancing system and to optimize the journal bearings, the sensibility analysis was applied. So, it were considered increases in the radial clearance of $10 \mu \mathrm{m}$ until $\mathrm{c}=45 \mu \mathrm{m}$, increases in the journal bearing length of $2 \mathrm{~mm}$ until $\mathrm{L}=35 \mathrm{~mm}$ and increases in the journal bearing diameter of $2 \mathrm{~mm}$ until $\mathrm{D}=28 \mathrm{~mm}$.

\section{RESULTS}

Doing the calculus for the studied mass balancing system it was verified that at $130{ }^{\circ} \mathrm{C}$, for the minimum radial clearance and for the maximum load, the maximum pressure reaches $23.269 \mathrm{MPa}$, which is much higher than the maximum value allowed, occurring eventually fatigue failures in the journal bearings. Applying the methodology and increasing the journal bearing length up to $35 \mathrm{~mm}$, the maximum pressure decreased to $14.619 \mathrm{MPa}$, as it can be seen in Fig. 1.

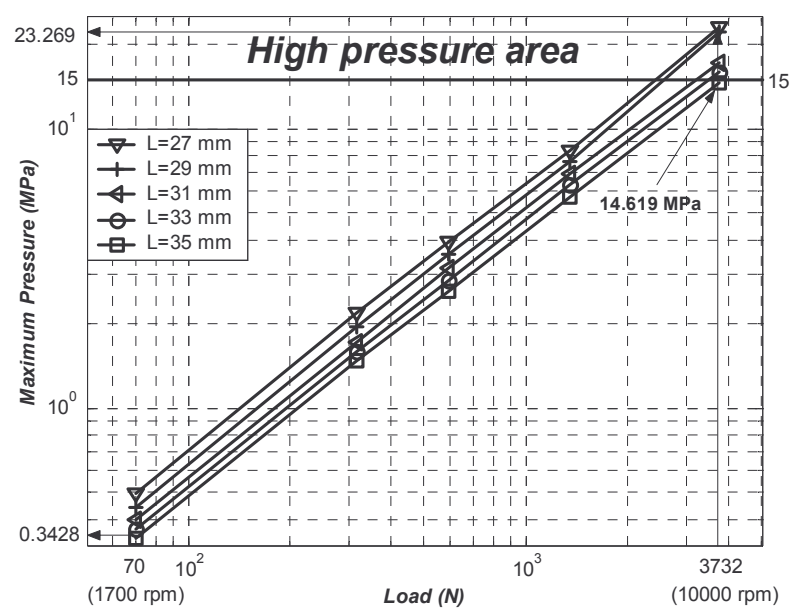

Figure 1. Maximum pressure versus applied load varying the journal bearing's length for $\mathrm{T}=130^{\circ} \mathrm{C}, \mathrm{c}=15 \mu \mathrm{m}$ and $\mathrm{D}=20 \mathrm{~mm}$
For the same operating conditions of temperature, radial clearance and load of the mass balancing system studied, it was verified that the minimum film thickness reaches 3.1380 $\mu \mathrm{m}$, which is less than the allowable value considered; nevertheless it's higher than the value from which the contact occurs. Applying the methodology it can be achieved a minimum film thickness of $5.18 \mu \mathrm{m}$ for a journal bearing length of $35 \mathrm{~mm}$ and for a journal bearing diameter of $24 \mathrm{~mm}$ at $130{ }^{\circ} \mathrm{C}$ and for a radial clearance of $45 \mu \mathrm{m}$.

Following the methodology it can be observed that increasing the radial clearance, the minimum film thickness increases of about $1 \%$, the power loss decreases of about $17 \%$ and the maximum pressure doesn't change. Increasing the journal bearing length, it can be observed that the minimum film thickness increases of about $9.5 \%$, the power loss increases of about $3 \%$ and the maximum pressure decreases of about $11 \%$. Finally, increasing the journal bearing diameter, the minimum film thickness increases of about $4 \%$, the power loss increases of about $75 \%$ and the maximum pressure decreases of about $0.7 \%$.

\section{CONCLUSIONS}

Using the described methodology one can conclude that: the maximum pressure it is mainly affected by the journal bearing's length, that the power loss it is mainly affected by the journal bearing's diameter and that the minimum film thickness it is affected by the journal bearing's diameter and length. Regarding the lubrication, these journal bearings should have circumferential grooves, because they are subjected to dynamic loads.

Finally, for the case study it can be concluded that the journal bearings should have the following dimensions: $\mathrm{L}=35$ $\mathrm{mm}, \mathrm{D}=24 \mathrm{~mm}$ and $\mathrm{c}=45 \mu \mathrm{m}$, allowing this way one increase of $65 \%$ in the minimum film thickness for $5.18 \mu \mathrm{m}$, one decrease of $70 \%$ in the maximum pressure for $6.96 \mathrm{Mpa}$ and one decrease of $4 \%$ in the power loss for $144.61 \mathrm{~W}$, in comparison to the standard definitions.

\section{REFERENCES}

1. Morais, L., 2003, "High speed hydrodynamic journal bearings optimization for mass balancing systems of diesel engines", Project report, Faculty of Engineering, University of Porto. (in Portuguese)

2. Ferreira, L.A., 2000, “Tribology - Annotations : Lubrication and Lubricants", Publindústria - Edições Técnicas, Porto, pp 103 - 150. (in Portuguese).

3. Stachowiak, G.W. and Batchelor, A.W., 2001, "Engineering Tribology", Butterworth - Heinemann, Woburn, pp $101-216$ and $669-722$.

4. ESDU, "Calculation methods for steadily loaded central circumferential groove hydrodynamic journal bearings", Item No. 90027, ESDU International, London, April 1995.

5. Avraham, H., 2003, "Bearing Design in machinery: Engineering Tribology and Lubrication" Marcel Dekker Inc, New York., pp $275-307$. 